\title{
Knowledge Management and Measurement: a Critical Review
}

\author{
Amr Arisha \\ Technological University Dublin, amr.arisha@tudublin.ie \\ Mohamed Ragab \\ Technological University Dublin, mohamed.af.ragab@gmail.com
}

Follow this and additional works at: https://arrow.tudublin.ie/buschmarart

Part of the Business Administration, Management, and Operations Commons, and the Other Business Commons

\section{Recommended Citation}

Arisha, A. and Ragab, M. Knowledge management and measurement: a critical review. Journal of Knowledge Management, Vol. 17 Issue: 6,

This Article is brought to you for free and open access by the School of Marketing at ARROW@TU Dublin. It has been accepted for inclusion in Articles by an authorized administrator of ARROW@TU Dublin. For more information, please contact arrow.admin@tudublin.ie, aisling.coyne@tudublin.ie,gerard.connolly@tudublin.ie.

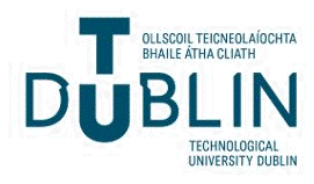




\section{Knowledge Management and Measurement: A Critical Review}

\section{Abstract}

\section{Purpose}

Knowledge is the currency of the current economy, a vital organisational asset and a key to creating a sustainable competitive advantage. The consequent interest in Knowledge Management (KM) has spurred an exponential increase in publications covering a broad spectrum of diverse and overlapping research areas. The purpose of this paper is to provide a literature review and categorised analysis of the rapidly growing number of KM publications, and offer a comprehensive reference for new-comers embarking on research in the field with a particular focus on the area of Knowledge Measurement.

\section{Design/Methodology/Approach}

A total of 350 articles published in peer-reviewed journals and conferences over the last decade are carefully reviewed, analysed and categorised according to their specific subject matter in the KM context.

\section{Findings}

KM research tends to fall in one of five categories: (1) Ontology of Knowledge and KM, (2) Knowledge Management Systems, (3) Role of Information Technology, (4) Managerial\& Social issues, and (5) Knowledge Measurement. Despite the accumulation of extensive publication efforts in some areas, a series of disagreements and a theory-practice gap are revealed as challenging issues that need to be addressed.

\section{Research Limitations/Implications}

The scope of this study does not cover KM research in its entirety due to the vast nature of the research field.

\section{Originality/Value}

This paper presents a new birds-eye view of the KM landscape through a comprehensive taxonomy of KM research providing researchers with new insights for future applied research, and offers a critical review of major knowledge measurement frameworks. 


\section{Introduction}

Knowledge has been recognised as a valuable organisational resource from a strategic perspective (James, 2004) and a foundation for competitive advantage in today's business environment (Erden et al., 2008). Its value is magnified by it being closely related to another important organisational resource in today's dynamic global markets - time. Today's organisations are viewed as "wellsprings of knowledge" (Leonard, 1995) and thus cannot afford to lose time "reinventing the wheel" (Dani et al., 2006) or looking for old knowledge they are unable to retrieve by trying to "know what they know" (Sieloff, 1999).

Such knowledge losses, which can have detrimental consequences for any organisation, can occur as a result of many internal and external factors such as lay-offs, resignations, retirements, restructuring and outsourcing (Delen and Al-Hawamdeh, 2009). When employees leave, they are likely to take away with them years of experience and valuable knowledge that could be priceless to their organisations (Du Plessis, 2005, Hofer-Alfeis, 2008). Attempting a valuation, a U.S. Fortune-500 company estimated the loss of only one experienced marketing manager to exceed $\$ 1$ million due to the loss of knowledge (Parise et al., 2006).The potential loss of knowledge is expected to increase as workforce mobility, employee turnover and layoffs caused by downsizing increase, especially during the current global financial crisis (Serban and Luan, 2002, Martins and Meyer, 2012).

The subsequent growing interest in Knowledge Management (KM) has resulted in an exponential growth in KM publications over the last decade at a rate of almost $50 \%$ per year (Bontis and Serenko, 2009, Serenko and Bontis, 2004, Zack, 1999). A study of research published in 11 key KM journals identified 3,109 unique authors affiliated to 1,450 institutions between 1994 and 2008 (Serenko et al., 2010). The real numbers of KM publications may be multiples of those reported, since a significant portion of KM research is published in non-KM journals ( $\mathrm{Ma}$ and $\mathrm{Yu}, 2010)$. This is because - unlike other fields - the KM field has no clear boundaries (Lloria, 2008) but rather a heterogeneous nature that creates overlaps with other domains (Figure 1). This paper therefore attempts to characterise KM as a crucial business area by presenting a comprehensive literature review and a categorised analysis of KM research publications. 


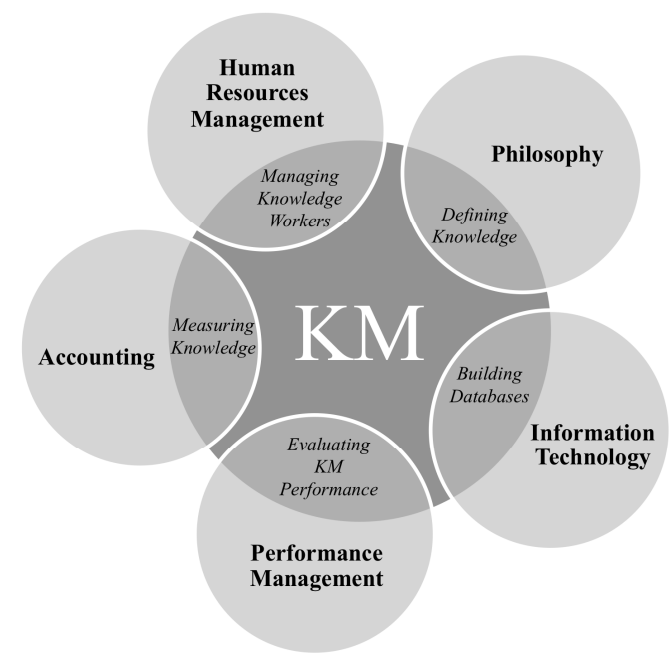

Figure 1: Overlapping areas between KM and other fields

\section{Methodology}

The literature review process was conducted in light of the frameworks proposed by Jesson et al. (2011) and Tranfield et al. (2003). First, a research plan was devised to outline the scope and methodology of the review and the publication selection criteria. The criteria for inclusion were English peer-reviewed journal and conference articles retrieved from the Emerald Insight and Science Direct databases and published during the period; 1995 to present. This time period represents the prosperous period of $\mathrm{KM}$ research $(\mathrm{Ma}$ and $\mathrm{Yu}$, 2010) with particular emphasison publications in the last five years (Figure 2). Non-academic research, publications in other languages or in other databases were criteria of exclusion. Database search used the general keywords knowledge management and knowledge measurement. In total, this study has extensively reviewed more than 350 references, of which 213 are cited in this article, with the majority (89\%) of references being peer-reviewed journal articles. Almost 50\% of the articles were published in the Journal of Knowledge Management, the oldest (Lambe, 2011) and highest ranked journal in the field (Bontis and Serenko, 2009). Other publications from theJournal of Intellectual Capital and Knowledge Management Research and Practice and key publications of books or reports in KM (i.e. top cited) were also included.

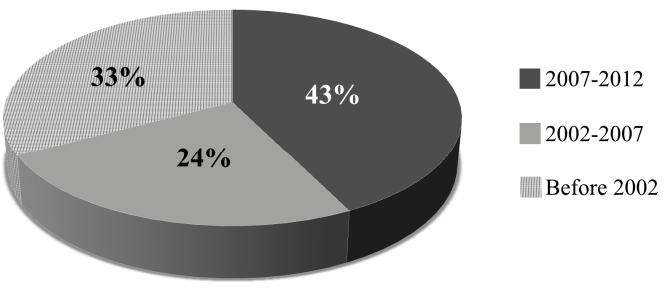

Figure 2: Chronological distribution of references 
A review and thematic analysis were carried on publications with an objective of developing acomprehensive framework. The inductive approach was used to classify articles and was not based on a predefined classification (Rynes et al., 2001, Crilly et al., 2010). As the review progressed, the authors developed the boundaries of a taxonomic framework of $\mathrm{KM}$ subdomains in which each paper was categorised under a certain theme according to its content and the taxonomy was iteratively refined. Since an exhaustive review of the KM literature is practically impossible due to the immense scope of the field (Kalling, 2003), this study adopted Glaser and Strauss's (1967) 'theoretical saturation' notion. They define saturation as being achieved when "no additional data are being found whereby the researcher can develop properties of the category" and he/she "becomes empirically confident that a category is saturated" and hence concludes the review when the contribution of further studies is perceived to add little value (Mitchell and Boyle, 2010). Analysis of each category in the framework has enabled the authors to critically conclude the key findings and highlight the potential future areas of interest in the domain with a particular interest in knowledge measurement.

\section{Classification of KM Literature}

The resultant proposed taxonomy presented a degree of similarity to that of Maier (2002) in the overall framework, however, there were still significant differences with regards to literature categories and subcategories. Overall, KM studies were classified into one of five categories: (1) Ontology of Knowledge and KM, (2) Knowledge Management Systems, (3) Role of Information Technology, (4) Managerial \& Social issues and (5) Knowledge Measurement (Figure 3).

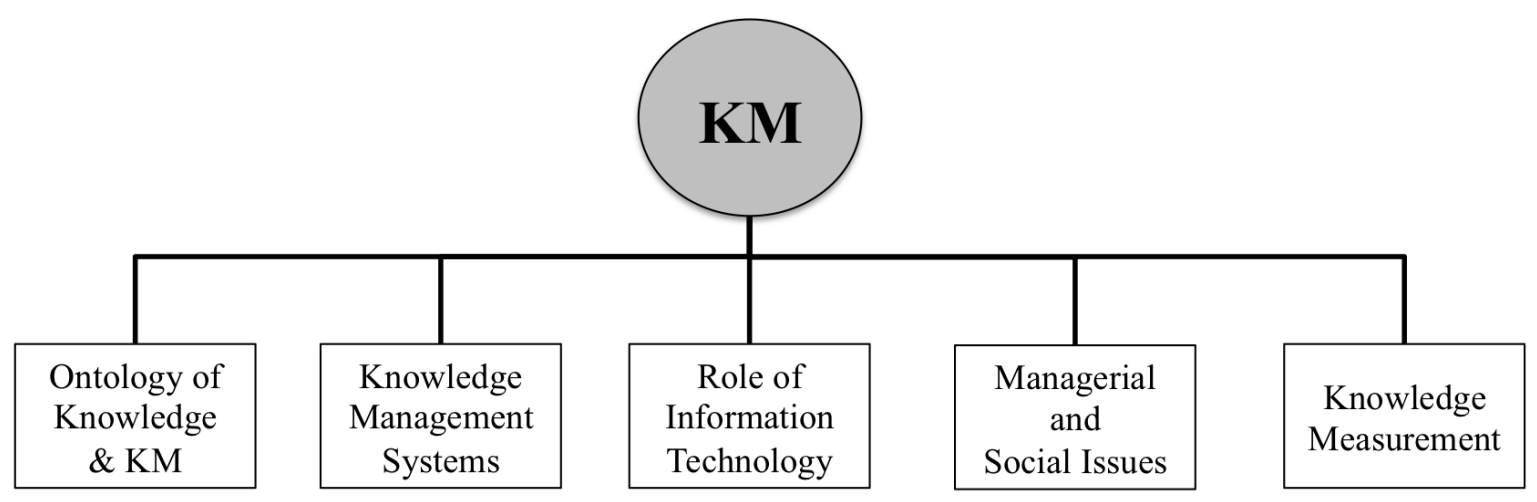

Figure 3: Classification of KM literature 


\subsection{Ontology of Knowledge and KM}

This category of the literature includes definitions, types and characteristics of knowledge and $\mathrm{KM}$ and grows from a controversy about the nature of knowledge that has remained unresolved since the age of the philosophers of Ancient Greece.A complex debate about the definition of knowledge is the subject of a dedicated branch of philosophy called epistemology (Zelic, 2005, Jakubik, 2007). The most common definition of knowledge is the top tier in a three-level hierarchy that begins with 'data' (i.e. raw facts), which, when processed, yields 'information' (Moteleb and Woodman, 2007), which, when combined with experience and judgement and used in decision-making, becomes 'knowledge' (Kidwell et al., 2000). Although this classical hierarchy is widely accepted in the literature, some authors still question the relationship between information and knowledge, pointing out that the distinction between them is vague in many contexts (Hicks et al., 2006, Faucher et al., 2008). Aside from seeing knowledge through this relational hierarchy, other authors define it as a state of mind (Schubert et al., 1998), a process(Zack, 1999), an object (Zack, 1999), a condition of access (McQueen, 1998), or a capability (Carlsson et al., 1996), among other definitions (Chang Lee et al., 2005).

There is similar debate about the classification of types of knowledge, but the most widely used is the tacit/explicit dichotomy (Polanyi, 1967). Explicit knowledge (EK) is that which can be codified and stored in various formats - such as printed manuals or electronic databases - and so can be transferred without losses(Stevens et al., 2010). Tacit knowledge (TK), on the other hand, lies in an individual's judgement and experiences and cannot be articulated or stored (Grant, 2007). It is what Polanyi describes as "we know more than we can tell." Despite being personal, embedded, contextually-bounded, TK can still be managed using appropriate methods (Johnson, 2007). Again, as in the case of the knowledge hierarchy, some authors still question the consistency of the tacit/explicit dichotomy and their interrelationship (Oguz and Sengün, 2011).The prominent SECI conversion model (Figure 4), formulated by Nonaka and Takeuchi (1995) based on this dichotomy, proposes that valuable TK resides within individuals and can add value only if converted to EK through one of four conversion modes (Diakoulakis et al., 2004, Mouritsen and Larsen, 2005). Despite having its challengers (Wilson, 2002), this model is widely used in the literature as a foundation for discussing KM. 


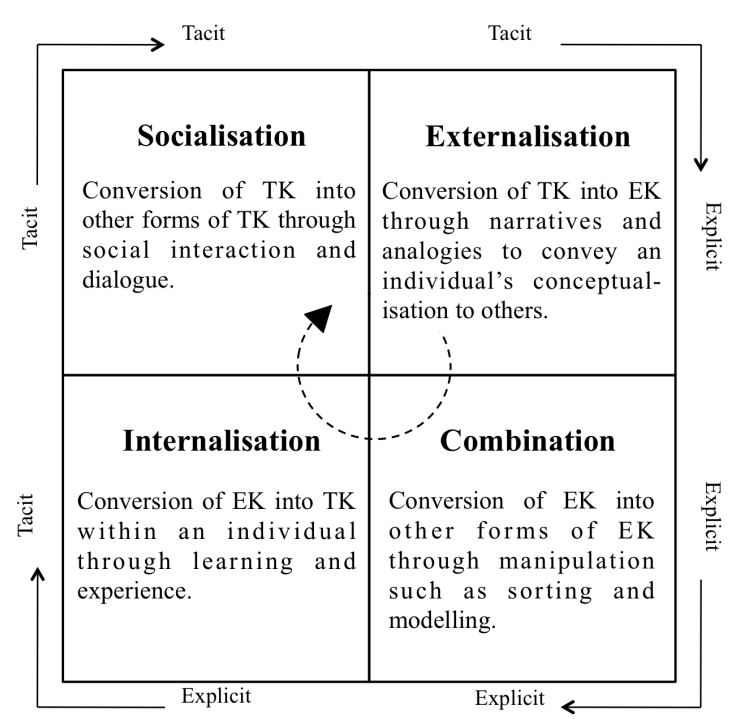

Figure 4: The SECI Model (Nonaka and Takeuchi, 1995).

Numerous taxonomies of knowledge - other than the tacit/explicit dichotomy - have been identified in the literature of this area. For example, Heisig(2009) identified 28 other knowledge dichotomies, including: individual/organisational, internal/external, used/unused, undocumented/documented, structured/unstructured, relevant/irrelevant and objective/subjective knowledge. Other taxonomies have included embrained/embodied/encultured/embedded/encoded knowledge (Blackler, 1995), catalogue/explanatory/process/social/ experiential knowledge (Millar et al., 1997), and the simple yet comprehensive 'know-what/know-why/know-how/know-who' taxonomy (Lundvall, 1996). Debates about the nature and types of knowledge have remained unresolved for decades, and are likely to continue, due to the philosophical nature of this area and its dependence on subjective views.

As with other resources, the need to manage the knowledge resource gave rise to the field of Knowledge Management (KM). The literature is rich with various definitions of KM, but one of the most simple and comprehensive definitions is " [a] conscious strategy of getting the right knowledge to the right people at the right time and helping people share and put information into action in ways that strive to improve organisational performance" (O'Dell et al., 1998). Organisations have always attempted to manage knowledge through documentation or archiving activities, but these initiatives were mostly fragmented and tended not to be managed under an organisation-wide KM rubric (Carlsson, 2003). KM differs from such activities in being a conscious and systematic approach to the capture, retention and transfer of knowledge (Bergeron, 2003). Notions of the 'right knowledge', the 'right people' and the 'right time' demonstrate the need to identify the required knowledge 
among the large amount of information an organisation creates every day (Duffy, 2000), who holds it, and when and how it should be transferred.

The definition above also makes an essential association between KM and corporate strategy, a link which ensures $\mathrm{KM}$ is oriented towards improving corporate performance and making a company's management and employees aware and aligned with its $\mathrm{KM}$ objectives ( $\mathrm{Du}$ Plessis, 2007, Kamara et al., 2002). KM contributes in the formulation of such strategy due to its key role in decision making, a managerial process that is significantly knowledgeintensive (Holsapple, 2001). Nicolas (2004) identifies three phases of decision making in complex situations - intelligence, conception and selection- all of which rely on KM processes, namely knowledge acquisition, knowledge sharing and knowledge utilisation.

$\mathrm{KM}$ is vital not only for the success of organisations, but also for the development of societies. The societal role of KM grows from the fact that knowledge is the foundation of economic progress and growth of communities in the current era (Romer, 1986). To meet the demands of a globalised economy, today's nations have to leverage the knowledge of their citizens and provide knowledge-related infrastructures such as education, apprenticeships, research programs, and ICT, all of which would be managed by KM (Wiig, 2007).

\subsection{Knowledge Management Systems}

A Knowledge Management System (KMS) is a managerial, technical and organisational system structured to support the implementation of KM within an organisation (Massa and Testa, 2009). The literature has identified three approaches to designing a KMS: codification, personalisation, people-finder, in addition to a hybrid approach.

The codification ('hard') approach focuses on the capturing and storage of knowledge in electronic repositories, making it available for retrieval and, due to its nature, tends to pursue EK (Shin, 2004). This approach adopts a 'people-to-documents' strategy, seeking to reuse knowledge by investing in building robust databases and rewarding employees who contribute to the IT-based KMS (Hansen et al., 1999). In contrast, the personalisation ('soft') focuses on the transfer of knowledge through face-to-face social interaction activities such as communities of practice and story-telling(Shin, 2004). This approach adopts a 'person-toperson' strategy aimed at sharing knowledge and nurturing innovation, and so is seen as the more suitable for the dissemination of TK (Massa and Testa, 2009). In this approach, moderate investment is made in IT as its function is only to connect people, and more 
investment is made in recruiting highly qualified human resources and rewarding them for sharing their knowledge (Hansen et al., 1999).

Conceding that not all knowledge can be articulated, and not wanting to neglect valuable tacit knowledge, the People-Finder KMS approach does not attempt to capture knowledge itself but instead aims to map the location of this knowledge within the organisation (BecerraFernandez, 2000). This approach tries to create a 'Knowledge Yellow Pages' to point those seeking certain expertise towards those within the organisation who hold it, and to ensure they are accessible for consultation or knowledge sharing (Lloria, 2008). To trace where knowledge is located within the organisation more accurately, some studies have analysed the flow of knowledge and the roles of different members in knowledge acquisition and sharing. They divided employees into external communication stars who acquire external knowledge and bring it into the organisation, internal communication stars who disseminate knowledge within the organisation, and gatekeepers who have the unusual capability to do bothtasks (Whelan et al., 2010). The literature presents sundry views as to the processes any KMS should incorporate. While different authors have identified between four and ten processes, all of them can be grouped under four core KM processes: (1) knowledge creation and acquisition, (2) knowledge storage and retrieval, (3) knowledge transfer and sharing, and (4) knowledge application (Alavi and Leidner, 2001).

Given the preceding approaches and processes, the literature presents a myriad of different KMS frameworks that attempt to provide a systematic solution for managing knowledge. It is generally observed that the majority of proposed KMS frameworks tend to be 'prescriptive' by providing outlines of the $\mathrm{KM}$ procedures firms need, but without always detailing specifically how they would be implemented (Holsapple and Joshi, 1999). Although some argue that a company must choose between a codification and a personalisation strategy in developing its KMS(Hansen et al., 1999), others (Snowden, 2002) believe both can be pursued simultaneously (Aidemark, 2009).Hence, a more recent trend is to design a 'holistic' KMS that would address all KM processes and would use a hybridisation of both codification and personalisation (Diakoulakis et al., 2004).

Besides proposing different approaches to KMS, numerous other discrepancies can be observed when reviewing the studies in current KMS literature. Authors disagree as to the processes that should be included in a KMS and their sequence, as well as in the terminology used. Consequently, a universally accepted KMS framework has yet to exist (Metaxiotis et 
al., 2005).In a step towards consensus on basic KMS principles, recent efforts have attempted to develop KM standards, such as the European Guide to good Practice in Knowledge Management published by the European Committee for Standardisation (Heisig, 2002).

\subsection{Role of Information Technology}

This is a grey area between management and IT literature that is populated with extensive research on the design and implementation of IT-based solutions and their role in KM. Computer science research in this area has investigated the development of new algorithms to improve the performance and ease of use of current KM solutions using such programming tools as data mining, artificial intelligence, expert systems, database technologies, search techniques, and modelling (Liao, 2003).Utilising these tools, a wide spectrum of software has been produced, each labelled as a 'KM solution'. Table1 summarises the features of each type of software and its KMS approach based on detailed research byLindvall et al. (2003), who concluded that no comprehensive KM package yet exists because of the variety of KM attributes a truly comprehensive IT suite would need to cover.

\section{TABLE 1: SOFTWARE TOOLS FOR KM}

The massive growth of the Internet has taken IT aspirations to another level in the KM domain, and new areas of research have emerged, particularly since the introduction of WEB 2.0 technologies based on user-generated content. With more than one billion Internet users, several authors have strongly encouraged businesses to adopt WEB 2.0 solutions, such as wikis and social networks, to manage knowledge emphasising its advantages that include ease of use, structured content, collaboration, tracking and revision capabilities (Grace, 2009, Levy, 2009).

Initially such ambitions led to unrealistic expectations of what IT could offer to the management of knowledge, and exaggerated predictions led some organisations to adopt entirely IT-based approaches to KM. Unfortunately, many of these initiatives failed considerably due to two main reasons; first, KM relies on cognitive processes exercised by the human brain and involves socio-cultural interactions that IT remains unable to capture (for an in-depth account of human cognitive processes please refer toKahneman (2011)). When technologies involved did not come as close to being comparable with the human brain as its proponents had hoped, it became evident that there is a limit to what technology could do for KM (Davenport and Prusak, 2000).In the same time, IT systems that focused only 
onknowledge that could be codified (i.e. EK), ignored people's valuable TK resources (Storey and Barnett, 2000). The second reason is that in taking an IT-based approach, some organisations overlooked the complexities of human behaviour by assuming people would be willing to share their knowledge, which in many contexts was not the case (Garcia-Perez and Ayres, 2010).

The consequential reporting of numerous cases of failure of IT-based KM approaches led to the general understanding that $\mathrm{KM}$ is not an IT issue. It became evident that depending solely on technological solutions would never lead KM initiatives to succeed because of the cultural barriers and organisational change issues that technology alone cannot solve (Beesley and Cooper, 2008, Cleveland, 1999, Lang, 2001, Syed, 1998, Zeleny, 2002, Fahey and Prusak, 1998, Call, 2005). This gave rise to a new, more moderate, attitude towards IT use in KM, where IT is viewed only as an important 'catalyst' (Tsui, 2005) to support KM initiatives. As Mohamed et al. (2010) conclude: "IT as a utopian panacea will fail. Equally, the KM initiative that undervalues IT will follow suit."

\subsection{Managerial and Social Issues in KM}

An Ernst \& Young survey of 431 US and European companies found that the gravest reported difficulties in organisations were 'changing people's behaviour', and the existence of 'inappropriate organisational cultures' (Ruggles, 1999). Therefore, studies in the fourth identified category in the KM literature examine the relationship between $\mathrm{KM}$ and other managerial and cultural aspects of an organisation that are vital for KM success. This stream looks at the social aspects of KM, particularly of knowledge sharing and transfer, and has received well-deserved interest and research intensity over the past few years.

A common major problem - and a starting point for research in this area - is the tendency of employees to hinder KM initiatives, which stems from their resistance to sharing their knowledge with others. The main reason for such knowledge 'hoarding' is people's fear of losing their "unique value" that would reduce their chances of promotion and increase those of others with whom they have shared their knowledge (Renzl, 2008, Hislop, 2009). Their fear may extend much further, as was shown by a case study in which employees expressed their perceptions that contributing to the company's KMS could (indirectly) cause them to lose their jobs (Damodaran and Olphert, 2000). This resistance is amplified by the fact that knowledge hoarding is not proscribed while knowledge sharing is mostly not recognised nor rewarded in today's organisations (Lam and Lambermont-Ford, 2010).In fact, in some cases 
knowledge exchange may be perceived negatively as wasting time in "chatting"(Davenport and Prusak, 2000). Those who are willing to share their knowledge may be inhibited by the lack of time needed to put it into a form suitable for sharing, unawareness of what knowledge needs to be shared (Levy et al., 2010), fear of publishing something confidential (Paroutis and Saleh, 2009), and the lack of an organisational culture and/or structure that fosters knowledge sharing (Ling, 2011).

To overcome these barriers and change human behaviour, in-depth research has been conducted in the area of overlap between KM and Human Resources Management (HRM). Based on the fact that 'people' are the main drivers of KM (Yahya and Goh, 2002), research in this area studiesHRM functions from a KM perspective. In the case of motivation, for example, studies focus on how to encourage employees to share their knowledge (Vilma and Jussi, 2012) and engage with KM initiatives (Sié and Yakhlef, 2009, Swift et al., 2010). The dominant view is that employees do not share their knowledge for nothing, and that knowledge is transferred through transactions that take place in a 'knowledge market' in which there are buyers and sellers (Barachini, 2009). The 'price' of sharing knowledge could be 'reciprocity', where the seller expects to receive something in return; 'repute', where the provider wants to be known as a knowledgeable person, or 'altruism', where the knowledge sharer simply derives personal satisfaction from helping others (Davenport and Prusak, 2000). Other studies have investigated the effect of other HRM functions - such as recruitment, retention and training - on the 'knowledge worker' and knowledge sharing (O'Donohue et al., 2007, Yigitcanlar et al., 2007).

Organisational culture has been identified as a fundamental determinant of the success or failure of KM, and extensive research has been conducted to identify cultures that promote knowledge sharing (Al-Adaileh and Al-Atawi, 2011). The general observationisthat knowledge sharing flourishes in less formalised, more decentralised (Chen and Huang, 2007) ad-hoc cultures (Tseng, 2010) that foster trust (Holste and Fields, 2010) and entrepreneurial attitude (Suppiah and Sandhu, 2011). At the national level, few researchers conducted comparative KM studies across different countries (Magnier-Watanabe et al., 2011). Others used the cultural dimensions developed by Hofstede et al. (1991) and found that knowledge transfer is more prevalent in collectivist than in individualistic cultures (Moss et al., 2007), and is impeded by cultural differences in other dimensions, such as uncertainty avoidance and power distance (Chen et al., 2010, Wang et al., 2011). 
Organisational structure has also been studied as being as important as culture in relation to KM success, and flat organisational structures with few hierarchal levels are generally found to promote more knowledge sharing since they enhance interaction and communication between employees (Claver-Cortes et al., 2007). Studies have also explored the most suitable structure for governing KM functions (Schroeder et al., 2012). One approach has been to establish a formal KM governance structure as part of the organisational structure headed by the Chief Knowledge Officer (CKO) to lead the company's KM efforts and report directly to the top management (Kannabiran and Pandyan, 2010). Others propose creating a hybrid organisational structure by retaining the company's traditional structure while organising a superimposed 'virtual' structure to manage KM activities (Mahesh and Suresh, 2009).

In another cluster of research in this category, some authors have tried to summarise the managerial factors required for KM to succeed. Ample numbers of case studies in this area offer a number of undisputed social and managerial factors that are seen as crucial for the success of KM initiatives, reported in the form of lists of 'success factors' (Al-Alawi et al., 2007), 'barriers and facilitators' (Damodaran and Olphert, 2000), 'required organisational capabilities'(Gold et al., 2001)or 'organisational enablers' (Kamhawi, 2012) that have been extracted from various examples of success and failure. Some researchers have gone further to specify separate success factors for each stage of KM implementation (Lin, 2011), while others have limited their studies to certain industry classes, such as small businesses (Evangelista et al., 2010, Susanne and Ingi Runar, 2012, Susanne and Stefan, 2012), projectbased companies (Ajmal et al., 2010), telecom (Al-Adaileh and Al-Atawi, 2011), accounting and banking (Chong et al., 2011, Paul Ihuoma, 2012), higher education (Cranfield and Taylor, 2008, Kidwell et al., 2000), hospitality (Hallin and Marnburg, 2008), construction (Dave and Koskela, 2009), law firms(Forstenlechner et al., 2009)and police force (Seba and Rowley, 2010) contexts. Based on the conclusions of several authors (Anantatmula and Kanungo, 2010, Bishop et al., 2008, Mullich, 2001, Quaddus and Xu, 2005, Mason and Pauleen, 2003, Xue et al., 2011), the main KM success factors reported are:

○ Understanding, defining KM and communicating its benefits.

○ Linking KM to the business strategy;

○ Defining criteria for organisational knowledge;

○ Managing both EK and TK;

○ Integrating KM with other initiatives;

○ Top management participation and support. 
- Recognising and rewarding knowledge sharing;

- Creating a culture of communication and team work;

○ Installing an appropriate IT Infrastructure to support KM;

- Adopting a holistic approach to KM that is not entirely dependent on IT;

- Appointing dedicated staff to champion the KM initiative and provide training;

- Providing standardised and documented KM policies and procedures to ensure clarity of roles and processes.

\subsection{Knowledge Measurement}

Knowledge measurement is one of - if not the - most difficult of KM activities (Chen et al., 2009). The fluid and intangible nature of knowledge makes its measurement an enormously complex and daunting task (Kankanhalli and Tan, 2005). Discussions of knowledge measurement are often coupled with the related concept of Intellectual Capital (Galbraith, 1969) which is generally defined as "knowledge, information, intellectual property, and experience that can be put to use to create wealth" (Stewart and Ruckdeschel, 1998). Intellectual Capital (IC) can be viewed as an organisation's 'stock' of knowledge at any particular time (Bontis, 2004), comprising knowledge that has been acquired and formalised to be used to create value and so gain competitive advantage (Chatzkel, 1998). Therefore, organisations implement KM processes to capture and disseminate knowledge 'flows' with the object of accumulating IC (Ahmed and Omar, 2011). The drivers behind IC measurement are viewed from two organisational perspectives: internal and external. From an internal perspective, managers may not know the value of their own IC, nor where it exists within their organisations, despite it being their main source of competitive advantage (Bontis, 1999).Accordingly, IC measurement models attempt to discover 'hidden' knowledge assets so they can be utilised more effectively to improve organisational performance (Edvinsson, 1997). When IC has been discovered, a measurement tool can continue to be crucial to evaluate KM's impact on increasing IC (Robinson and Kleiner, 1996)and to convince top management of the value of KM (Liebowitz and Suen, 2000). The enormous growth in KM expenditure - estimated in billions (Poston and Speier, 2005) - has been coupled with strong demands for solutions that provide robust justifications for the massive costs of KM (Khalifa et al., 2008).

From an external perspective, there is a widespread view that a company's value could only be assessed if intangible assets are taken into consideration. This view has emerged because 
of the wide gaps between companies' book and market values, where the ratio of the latter to the former has multiplied in the past decade (Baruch, 1997) as in the recent example of Facebook's billion-dollar acquisition of Instagram, a small photo-sharing smartphone application start-up. Generally Accepted Accounting Principles (GAAP) are criticised for not reflecting a firm's real value by only reporting physical assets on the balance sheet and disregarding intangibles ones, and also for reporting investments in IC (such as KM programs) as costs to be deducted from profit despite IC being an 'asset' that can be exploited to generate value. The "gap in the GAAP" (Skyrme, 2003) conundrum has led a number of researchers to propose alternative accounting methods that would reveal a company's 'true' value (Boda and Szlavik, 2007). The literature offers a plethora of knowledge measurement methods, where three main approaches are identified: (1) Financial Methods, (2) IC Methods, and (3) Performance Methods.

\subsubsection{Financial Methods}

This first type of research uses financial models to calculate an overall value for a company's IC using information from its financial statements. The following are the most prevalent methods:

\section{Tobin's Q}

Developed by the Nobel laureate economist James Tobin, Tobin's Q (Tobin, 1969) is a tool to evaluate investment decisions that measures a company's market-to-book ratio, but values tangible assets using their replacement cost rather than their book values (Luthy, 1998). Tobin theorises that a $\mathrm{Q}$ that is higher than one and is higher than that of competitors indicates the company possesses an 'intangible advantage' with which it can create more value than can its rivals. This advantage is its IC. Using market values to calculate Tobin's Q relates IC to stock prices, which may fluctuate due to countless factors, so Tobin's Q has been criticised for being a measure that "rises and falls with market exuberance" rather than being an appropriate method for measuring IC (Lev and Feng, 2001).

\section{$\underline{\text { Economic Value Added (EVA) }}$}

EVA (Stewart, 1994) is a financial measure originally introduced as an indicator of shareholder value created (Stern et al., 1995). It involves applying 164 adjustments to traditional balance sheets to account for intangibles, for example by adding back research and development costs to assets (Skyrme, 2003). EVA is then calculated by deducting the cost of capital from operating profit (Weaver, 2001). EVA cannot be used to measure IC directly; 
rather it can only suggest that an increase in EVA is an indicator of efficient management of IC (Chen et al., 2004). Since this link remains questionable, some authors conclude EVA is unsuitable as an IC indicator (Hong Pew et al., 2008).

\section{Human Resource Accounting (HRA)}

Originating in the 1960s, the objective of HRA (Hermanson, 1964) is to use financial data to quantify the economic value of people as 'human assets' (Flamholtz et al., 2002). Researchers have suggested three types of HRA models: cost models, market models and income models. In cost models, human capital is valued as the cost of acquiring human assets (i.e. their recruitment and training) or, alternatively the discounted value of employees' gross compensation (Bontis, 1999). Market models equate human value with cost of buying an individual's services from the market, for example via consultancy. Finally income models use the present value of the revenues a person is expected to generate while working for a company. HRA has been criticised as being dependent on a multitude of assumptions including employee service life, forecasted revenues, and of equating value with cost which lowers its reliability and may lead to results that are skewed by subjectivity (Mayo, 2001).

\section{Value Creation Intellectual Coefficient (VAIC)}

VAIC is a value added and IC evaluation method proposed by Ante Pulic (2000) that aims to measure how efficiently financial and intellectual capital are utilised to generate value for the company through the calculation of a series of formulae listed in Table 2 (Ståhle et al., 2011).

\section{TABLE 2: VAIC CALCULATION STEPS}

It should be noted that VAIC is limited to providing an overview of IC and identifying broad areas where value creation deficiencies exist. Pulic himself suggests deeper IC monitoring requires complementing VAIC with another IC measurement tool (Skyrme, 2003).

\subsection{2. $\underline{\text { IC Methods }}$}

The second approach, IC models, split a company's value into financial and intellectual capital, and then break down the latter into different elements which are evaluated individually (Luthy, 1998). The majority of such models tend to apply at least the first two of the following four processes: (1) IC Classification (2) Metric Development (3) Aggregation (4) Financial Valuation (Figure 5). 


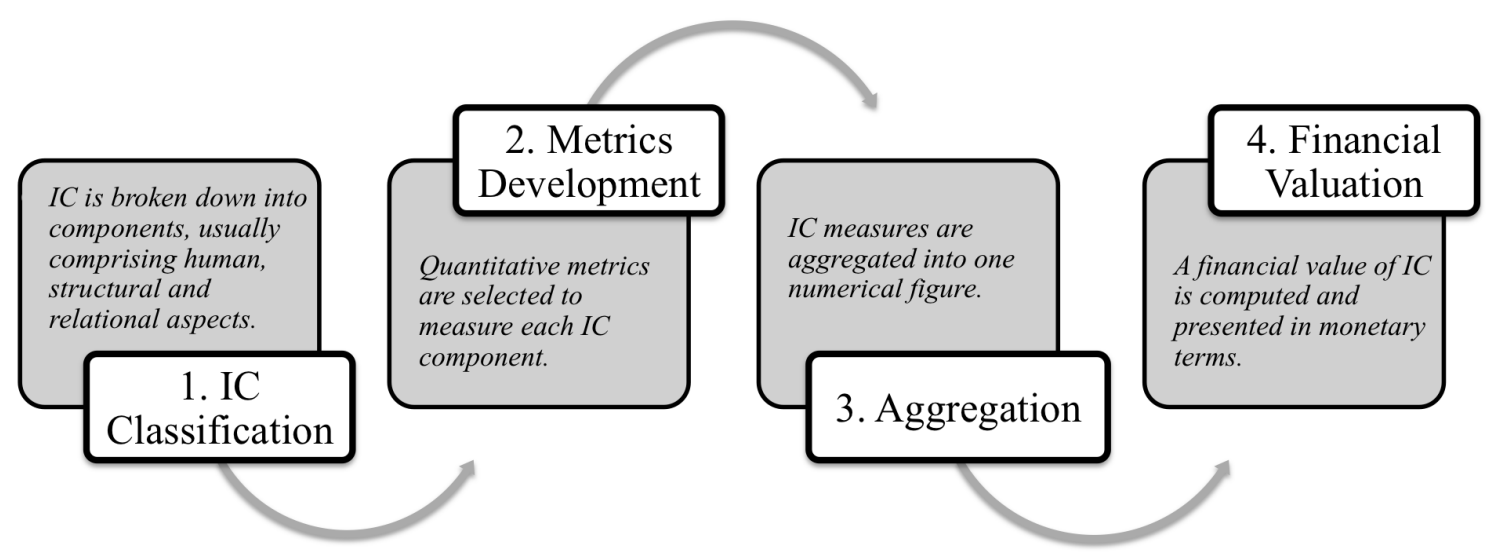

Figure 5: IC methods' main processes

When classifying IC, most authors agree with the tripartite classification proposed by Stewart (1998), in which IC is broken down into Human Capital (HC), Structural Capital (SC) and Relational Capital (RC) (Kwee Keong, 2008). HC includes the combined knowledge, skills and abilities that employees possess (Luthy, 1998), and is an important source of an organisation's innovation (Bontis, 1998). Since HC cannot be 'owned' by the organisation, it is lost when employees leave (Carson et al., 2004). SC (also referred to as Organisational Capital) is the supportive infrastructure - physical resources, information systems and organisational processes - the company makes available for its employees (Kannan and Aulbur, 2004). In contrast, SC is owned by the organisation, and so has been referred to as "knowledge that doesn't go home at night" (Stewart and Ruckdeschel, 1998). RC (also referred to as Customer Capital) refers to the combined value of an organisation's external relationships with stakeholders, such as suppliers and customers, who are valuable sources of both revenue and market knowledge for the organisation.

Following classification, sets of quantitative metrics are developed to measure each IC component. Metrics could be direct counts, monetary values or ratios/percentages (Lerro et al., 2012). In cases where metrics measure a qualitative attribute (such as motivation) scalebased surveys are used to convert qualitative values into quantitative figures. The next step in many frameworks is to aggregate all these IC measures into a single quantum, using different methods (averages, weighted averages, etc.). Some models then attempt a final IC valuation in monetary terms or propose a correlation between the computed value of IC and that of the company. An extensive literature review found the widely cited frameworks summarised in Table 3 to be the 'key' models in this area (Marr et al., 2004).

\section{TABLE 3: IC MEASUREMENT FRAMEWORKS}


Cited more than 3,000 times, the Skandia Navigator is the most prominent attempt to measure IC. Led by the world's first corporate IC director, the Swedish Insurance company Skandia AFS was the first to publish an IC supplement to its shareholders with its annual report in 1997 (Hawkins, 2001)usinga framework that applies all four processes in considerable detail. Roos et al. (1998) followed this initiative with their IC Index, which attempted to offer a more generic and flexible framework that would overcome some of the Navigator's drawbacks. The IC Rating (Jacobsen et al., 2005), Knowledge Assets Map (Marr et al., 2004), Intangible Assets Monitor (Sveiby, 1997), and its subsequent Modified Intangible Assets Monitor (Petty and Guthrie, 2000)frameworks limit their scope to internal reporting to allow top management to assess the status of a company's IC and assist in decision making. They do not target external presentation of the company's IC and thus only implement the first two processes (Classification and metric development). Finally, the Technology Broker IC Audit (Brooking, 1996) adopts an extensive auditing approach to IC measurement and applies HRA methodologies to value its unconsolidated components financially.

In addition to the aforementioned frameworks, a few more recent efforts are also noteworthy. In Germany, the Ministry of Labour and Economics supported the Wissensbilanz project, which aimed to instruct German SMEs on how to systematically evaluate and capitalise on their IC to enhance the competitive advantage of German companies. The project used The German IC Business Model as a framework that provides a systematic process by which companies would be able to visualise intangible factors that create value. It also provides a platform for decision-making that considers both tangible and intangible assets. The project and its associated website (www.akwissensbilanz.org) are acknowledged by German companies as a good tool to use for higher returns and cost savings (Edvinsson and Kivikas, 2007). In Spain, Viedma-Marti integrated the concept of benchmarking into KM by introducing the Intellectual Capital Benchmarking System (ICBS) in which companies would not directly measure IC, but rather benchmark their IC against 'world class best competitors' within the same business using a set of criteria and questionnaires(Marti, 2001, Marti, 2004, Martí, 2007). The ICBS framework has been validated and implemented successfully in a number of European enterprises.

For further literature reviews on knowledge and IC measurement, the authors recommend the comprehensive works by Skyrme (2003) and Andriessen (2004). In his report Measuring 
Knowledge and IC, David Skyrme presents more than 30 measurement models in addition to measurement case studies from over 35 organisations worldwide. Similarly, Daniel Andriessen's book Making Sense of Intellectual Capital reviews 25 valuation methods and provides a detailed account of a project in the Netherlands aimed at the development of a new method for valuing intangibles. His work is described by renown IC Scholar GoranRoos as "one of the most synthesising books on this important but challenging topic." (Andriessen, 2004).

\subsubsection{Human Capital Methods}

Adopting the view that $\mathrm{HC}$ is the most important form of IC, and the antecedent from which the other forms evolve (Baron, 2011), human capital models focus solely on measuring HC.The following are a few examples:

\section{Human Capital Readiness (HCR)}

The HCR report was developed as an extension to the Balanced Scorecard with a focus on HC, and so is also referred to as the HR Scorecard (Norton, 2001). The report assesses five HC areas: strategic skills and competencies, leadership, culture and strategic awareness, alignment of goals and incentives, and strategic integration and learning using a set of metrics (Skyrme, 2003). It also aims to evaluate the relationship between an organisation's HR strategy and its overall corporate strategy, and how the former contributes to the latter.

\section{Human Capital Index (HCI)}

Based on their work with 750 organisations over a period of three years, HR consultants Watson Wyatt identified a correlation between $46 \mathrm{HR}$ practices and growth in shareholder value (Wyatt's, 2001, Wyatt, 2001). They grouped practices into five dimensions, and noted that influence on financial performance varied from one dimension to another. Their HCI uses a questionnaire to measure and evaluate each practice within organisations they advise. This cannot not be considered as an explicit measure of $\mathrm{HC}$, but rather an assessment of HR actions that increase $\mathrm{HC}$, and so result in an increase in financial value.

\section{$\underline{\text { Human Capital Monitor (HCM) }}$}

Mayo (2001) describes his proposed Human Capital monitor (HCM) framework as a "means of recognising the vital contribution of people to value creation." The model is based on the following equation:

People as Assets + People Motivation and Commitment $=$ People Contribution to Added Value 
The first parameter is measured as follows:

Human Asset Worth = Employment Costs (EC) x Individual Asset Multiplier (IAM)/1000

where EC $=$ Base Salary + Value of Benefits + Employer Taxes, and the IAM is a weighted average assessment of an employee's capability, potential, contribution and values alignment. Five factors are assessed through a mix of metrics and surveys to measure 'motivation and commitment': leadership effectiveness, practical support, nature of the workgroup, culture of learning and development; and systems for rewards and recognition. The 'contribution to added value' is measured though a set of financial and non-financial metrics. The HCM has been criticised for making certain assumptions and a degree of subjectivity, but has the advantage of being one of very few frameworks that attempt to measure human capital at the individual employee level, rather than collectively.

\subsubsection{Performance Methods}

Although a number of researchers affirm that knowledge is measurable by developing appropriate frameworks, others adopt the view that it cannot be measured byarguing that its intangible and multifaceted nature would thwart any measurement technique (Liebowitz and Wright, 1999, Huang et al., 2007). Instead, they recommend that efforts should be directed towards measuring the impact of knowledge when applied (Carrillo et al., 2003). They note that the bulk of KM literature hypothesisesa causal link between KM and improved performance, despite the fact that very little research has made an explicit correlation between them (Kalling, 2003, Andreeva and Kianto, 2012). Even those who conclude empirically that KM does create value are unable to quantify that value (Ibrahim and Reid, 2009).Hence, the fourth and final type of knowledge measurement research aims to measure the effects of $\mathrm{KM}$ on organisational performance.

Frameworks in this domain measure the performance either of KM processes or of their outcomes (Goldoni and Oliveira, 2010). Process performance measures are a type of 'leading' measure that monitor the performance of a KM initiative and provides immediate feedback on KM implementation allowing management to take actions in 'real-time' (Vestal, 2002). Examples of process metrics include statistics on KMS usage and the number of communities of practice. Usage metrics are more oriented towards IT-based KMS, and assume that the more people use a KMS, the more knowledgeable they become, which in turn improves organisational performance. But significant KMS failure rates indicate that such simplistic assumptions may be highly misleading (Khalifa et al., 2008). Process measures are 
only useful in providing an insight into the engagement of employees in a KM initiative, but do not establish any tangible linkage between KM activities and corporate performance.

Output performance measures, on the other hand, are 'lagging' indicators that demonstrate the results of KMS implementation in retrospect (Vestal, 2002). Their underlying logic is the comparison of performance before and after the implementation of a KM initiative to examine its effect on the organisation. Research in this area links Performance Management (PM) to KM, because the main emphasis is not on the KMS, but rather on determining how performance should be evaluated. In light of the taxonomy suggested by Huang et al. (2007), KM performance measurement methods are presented in the following classification:

\section{Quantitative Methods}

Classic PM methods measure performance using quantitative financial indicators, such as stock price, profitability, or return on investment from data taken from financial statements and annual reports. For example, Feng et al. (2004) compared historical financial data of KMS adopters and non-adopters and established a link between KM and stability of financial performance, while Chang Lee et al. (2005) reported an empirical correlation between KM processes and stock prices. Petra and Annelies (2012) used the financial data of 705 Belgian firms to demonstrate that KM has an "indirect positive impact" on financial performance that exceeds the costs associated with KM on the long term.

Quantitative methods have also been used to measure non-financial indicators such as reductions in cycle time or complaint numbers. These numerical methods have the advantage of minimising subjectivity, as no human opinion is involved. Nevertheless, the causal links they construct have still been criticised for obscurity in assuming that positive effects - such as sales increases - could be attributed particularly to KM, an assumption that is viewed as untenable because it overlooks the array of exogenous factors that may be affecting an organisation simultaneously (Yu et al., 2007).

\section{Qualitative Methods}

A number of KM studies use such qualitative methods as surveys, questionnaires or interviews to measure performance improvements. KM performance is evaluated based on respondents' opinions and relies to a large extent on their perceptions of the improvements KM has made to their organisations. The influences of various KM factors and processes on performance suggested by such qualitative studies are quantified using analysis techniques 
including Analytic Hierarchy Process, the more general Analytic Network Process (Wen, 2009), Partial Least Squares (Sangjae et al., 2012)and Structured Equation Modelling (Fugate et al., 2009). Zack (1999), for example, surveyed 88 executives and established a relationship between $\mathrm{KM}$ and both organisational and financial performance from the results.More recently, Mills and Smith (2011)surveyed 189 managers and used the same technique to assess the links between specific KM resources and performance. Despite being perceptual, qualitative methods are widely accepted in this type of research, as they provide stronger indications of causality between $\mathrm{KM}$ and corporate performance than quantitative methods (Yu et al., 2007). Nevertheless, they have been criticised for their dependence on individual judgements, with the associated dangers of subjectivity and bias (Kannan and Aulbur, 2004).

\section{Balanced Scorecard}

The Balanced Scorecard (BSc) is presented in a category of its own because of its multidimensional nature in comprising quantitative, qualitative, financial and non-financial measures. Pioneered by Kaplan and Norton (1995), the BSc is one of the most popular and widely cited PM frameworks (Roy et al., 2003). It offers a systematic methodology that uses strategy-linked leading and lagging key performance indicators (KPIs) to measure performance from four perspectives: financial, customer, internal business processes and learning \& growth. Goals and objectives are documented and KPIs measured for each of the four dimensions in the light of the corporate strategy. While the $\mathrm{BSc}$ is one of most comprehensive and effective frameworks to measure performance, it still cannot provide explicit links to KM. It should be noted that the learning and growth component of the BScwhich measures aspects such as innovation and employee development - has led some KM authors to classify the BSc as an IC measurement tool in itself (Hong Pew et al., 2008).

The above examples demonstrate that despite the numerous attempts, a convincing $\mathrm{KM}$ performance measurement method has yet to be developed, leaving a gap in the literature that needs to be filled with a clear technique (Zack et al., 2009). This gap is clearly felt in industry as a recent study has shown that only $4 \%$ of executives rate their company's performance as good in measuring the impact of KM (Harlow, 2008). 


\section{Discussion}

Based on an in-depth review of the literature, a few trends emerge. First, there is a lack of consensus on elementary issues in KM. While disagreements on theoretical, and rather philosophical, concepts are present in every domain, the KM community has failed to agree on the core concepts that could act as foundations for the field's further development. Authors disagree on KMS approaches, on terminology and even on the main elements and processes of a KMS. Hazlett et al.(2005) once stated that KM is stuck in a state of "prescience" because of the disagreements about fundamental issues within KM that hamper the progress of the field and their proposition continues to remain valid. It is noted however that, unexpectedly, there is a higher level of agreement on secondary issues, such as the role of IT in $\mathrm{KM}$ and the factors that contribute to the success of organisational KM.

Furthermore, the KM domain seems to be currently challenged by a theory-practice gap. This gap has several indicators, one of which is that the vast majority of KMS frameworks are presented in conceptual form, and do not offer action plans for actual implementation. The fact that they are characterised by a high degree of theoretical abstraction creates a gap between the proposed concept and its pragmatic application in the real world (Booker et al., 2008), which could be attributed to the minimal engagement of business professionals in KM research. An extensive study of 2,175 journal articles revealed a significant drop in practitioners' contributions to KM literature, from 33\% in 1998 to only $10 \%$ in 2008 - and more shocking is that only $0.33 \%$ of $\mathrm{KM}$ research involves field studies (Serenko et al., 2010). As a consequence of this 'disconnect', KM practitioners face difficulties in using academic KM findings in their organisations, and perceive a significant portion of KM research as "irrelevant" (Booker et al., 2008). This putsKM at risk of being seen as a purely theoretical field with limited practical applicability.

Overcoming these issue calls for efforts in two parallel directions. The first is in the building of the KM theoretical foundation in a manner that accommodates the current diversity in KM paradigms. A number of authors, such as McIver et al (2012), have proposed conceptual models that integrate the "divergent streams" of KM research. Agreement on core theoretical concepts should be coupled by a degree of standardisation in KMS parameters that could act as a foundation on which authors could build universal frameworks. A general opinion seems to be forming that single-approach KMS have proved futile, and so future KMS designs 
should adopt a holistic approach that amalgamates technology-based and people-oriented practices.

The second direction of research should be towards more practical work to address an existing gap between KM theory and practice. The drop in practitioner contribution and field study research reported by Serenko et al.(2010) is a critical trend that has to rectified by more engagement with industry in the KM domain. Managers' contribution to KM framework development is crucial to ensure a degree of applicability and to avoid the development of purely theoretical models that wouldonly be of interest to academics. Furthermore, the scope of new KM models should be extended to incorporate detailed guidance to practical implementation and, where possible, accounts of precedent cases where such models where already validated and produced viable results. New models should be comprehensive yet straightforward enough to be understood by all those who will apply them, who will not necessarily be KM experts. Analogously, research should aim to produce a framework targeted at acquiring widespread acceptance and becoming a global standard for KM, in the same manner the Balanced Scorecard is for Performance Management.

When focusing on knowledge measurement, it is evident that this area has received deserved attention over the last decade from the Accounting, HR and Performance Management perspectives. Financial models can provide succinct and unbiased overviews of an organisation's IC and are beneficial in investment decisions and benchmarking. However, they do not always clarify where problems exist and the value-adding contribution (or lack of) of different IC components, so do not provide clear roadmaps of what corrective KM actions should be implemented (Kannan and Aulbur, 2004). Performance models provide some indications of correlations between $\mathrm{KM}$ and performance, but can suffer from being built on the questionable assumption that changes in organisational performance are solely due to $\mathrm{KM}$ disregarding the (perhaps many) other possible endogenous and exogenous influences on firm performance (Yu et al., 2007).IC models, and their subset of HC models, provide deeper insights about an organisation, but are critiqued for only providing a 'snapshot' evaluation of an organisation's knowledge, and so only reflecting its static knowledge stocks without considering the dynamic element represented in its knowledge flows(Lerro et al., 2012). Future IC measures should aim to assess knowledge flows along with knowledge stocks by reflecting the dynamics of knowledge creation and transfer within organisations to avoid drawing only a static picture of IC. 
The literature also elucidates that IC models are confronted by few trade-offs. The first is between internal monitoring and external presentation as objectives of knowledge measurement. Ideally, knowledge measurement models should be suitable for both, assuming that organisations would disclose the value of their IC voluntarily, even if not required to by current accounting standards. But a company would never publish information about its IC if it was declining in value for fear of the harmful consequences for both its corporate image and stock price. This is probably why Skandia has not published an IC report since 2002, when its share price dropped significantly (Dumay, 2012). Moreover, accounting fraud scandals (like those at Enron and WorldCom) have made it very unlikely that accounting standards will change in the near future to incorporate intangibles, due to fear of biased valuations being used to manipulate financial information (Martin, 2004). One could therefore conclude that IC measurements for external reporting are still unreliable. This is not to demean the importance of the financial valuation of knowledge, but to suggest they should be oriented towards internal management to avoid the above-mentioned pitfalls and to ensure a higher degree of objectivity and transparency in identifying and reporting the value of knowledge assets.

The second trade-off is between generalisability and adaptability. Standardised frameworks that are designed to be generic (to allow benchmarking) have been criticised for not being adaptable to the particular circumstances of certain industries, markets or organisations. On the other hand, models that offer innate methods by which they can be tailored to a particular organisation's nature, industry and strategy are criticised for lacking generalisability, since cross-firm comparisons become impossible or at least inaccurate. Since, knowledge that is priceless in a certain contextual setting may be irrelevant in another, the second approach is still viewed as more effective because it considers the highly contextual nature of knowledge (Iske and Boekhoff, 2002).It is therefore proposed that knowledge measurement frameworks must incorporate embedded adjustments to organisational environment and strategy. If also only aimed at internal assessment, as previously recommended, the lack of model universality would no longer be a major drawback.

Finally, a common feature of all knowledge measurement approaches is an exclusive emphasis on knowledge measurement at the organisational level. In their classic work more than a decade ago, Nonaka and Takeuchi (1995)stated that "an organisation cannot create knowledge on its own without individuals." Since then, there has been widespread agreement 
that knowledge is created and resides within individuals (Ajmal et al., 2010), yet only very few measurement models are aimed at the foundational wellspring of knowledge: the knowledge worker (Kannan and Aulbur, 2004). Individual knowledge measurement is hence identified, as a central subdomain in KM, yet remains relatively under-explored.

\section{Conclusion}

This research offers a birds-eye view of the KM landscape through taxonomy of KM research providing researchers with a map (Figure 6) of the current literature and insights into future research. The paper presents a classification of KM publication into five areas: (1) Ontology of Knowledge and KM, (2) Knowledge Management Systems, (3) Role of IT, (4) Managerial \& Social issues, and (5) Knowledge Measurement.

The scope of this research study does not cover KM research in its entirety due to the vast nature of the field and thus has the limitation of being restricted to articles retrieved from the Emerald Insight and Science Direct databases. Accordingly, a number of KM publications may fall outside the proposed taxonomy. Content analysis was conducted by the authors using the theoretical saturation approach and may include a degree of bias with respect to the categorisation of publications. Yet, overall the authors find it reasonable to assume that the review process covered a significant and representative proportion of KM published studies. In the area of knowledge measurement, the proposed taxonomy could be further developed to offer a deeper understanding of research in this cluster.

Despite the limitations, the taxonomy developed in this paper provides an integrative and comprehensive review that can assist future research. Disagreements on fundamental issues and a theory-practice gap are major issues that confront KM researchers and practitioners and need to be further explored. There is an urge for $\mathrm{KM}$ research to reach a consensus on $\mathrm{KM}$ core concepts and, in parallel, provide today's business world with simple and pragmatic solutions to current KM challenges. In the subdomain of knowledge measurement, several areas of potential improvement have been identified for most knowledge measurement models. There is a need for new knowledge measurement models which incorporate measures of dynamic knowledge flows, embedded adjustments to organisational environment and strategy, and be directed more towards the individual knowledge worker and not focus solely on the organisational level. 


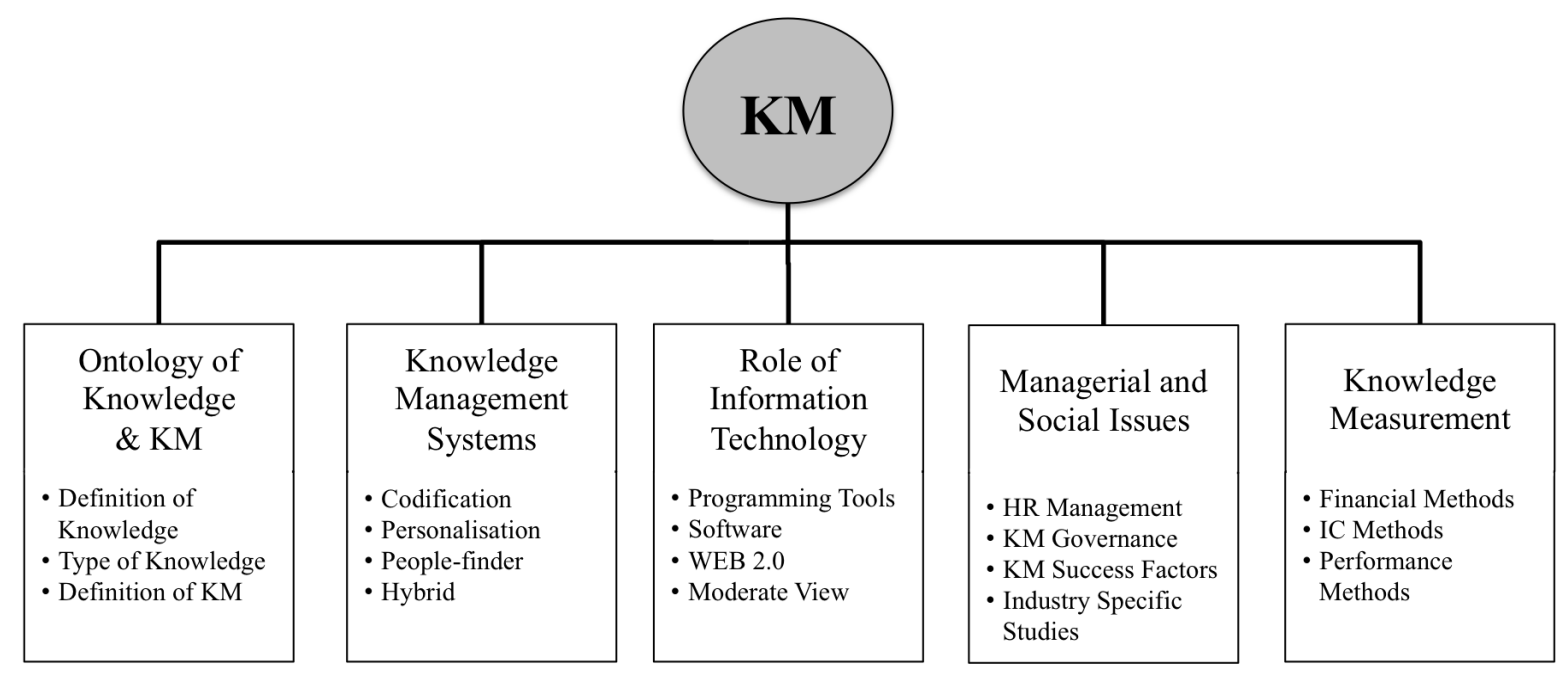

Figure 6: KM literature map

\section{References}

- Ahmed, A. S. S. \& Omar, E. M. K. (2011). "Understanding the knowledge management-intellectual capital relationship: a two-way analysis". Journal of Intellectual Capital, Vol. 12, pp. 586-614.

- Aidemark, J. (2009). "Knowledge Management Paradoxes". Electronic Journal of Knowledge Management, Vol. 7, pp. 1-10.

- Ajmal, M., Helo, P. \& Kekale, T. (2010). "Critical factors for knowledge management in project business". Journal of Knowledge Management, Vol. 14, pp. 156-168.

- Al-Adaileh, R. M. \& Al-Atawi, M. S. (2011). "Organizational culture impact on knowledge exchange: Saudi Telecom context". Journal of Knowledge Management, Vol. 15, pp. 212-230.

- Al-Alawi, A., Al-Marzooqi, N. \& Mohammed, Y. (2007). "Organizational culture and knowledge sharing: critical success factors". Journal of Knowledge Management, Vol. 11, pp. 22-42.

- Alavi, M. \& Leidner, D. E. (2001). "Review: Knowledge management and knowledge management systems: Conceptual foundations and research issues". MIS quarterly, Vol., pp. 107-136.

- Anantatmula, V. \& Kanungo, S. (2010). "Modeling enablers for successful KM implementation". Journal of Knowledge Management, Vol. 14, pp. 100-113.

- Andreeva, T. \& Kianto, A. (2012). "Does knowledge management really matter? Linking knowledge management practices, competitiveness and economic performance". Journal of Knowledge Management, Vol. 16, pp. 617-636.

- Andriessen, D. (2004). Making sense of intellectual capital: designing a method for the valuation of intangibles, Routledge.

- Barachini, F. (2009). "Cultural and social issues for knowledge sharing". Journal of Knowledge Management, Vol. 13, pp. 98-110.

- Baron, A. (2011). "Measuring human capital". Strategic HR Review, Vol. 10, pp. 3035.

- Baruch, L. (1997). "The old rules no longer apply". Forbes ASAP, Vol. 159, pp. 
- Becerra-Fernandez, I. (2000). "The role of artificial intelligence technologies in the implementation of people-finder knowledge management systems". KnowledgeBased Systems, Vol. 13, pp. 315-320.

- Beesley, L. \& Cooper, C. (2008). "Defining knowledge management (KM) activities: towards consensus". Journal of Knowledge Management, Vol. 12, pp. 48.

- Bergeron, B. P. (2003). Essentials of Knowledge Management, Wiley.

- Bishop, J., Bouchlaghem, D., Glass, J. \& Matsumoto, I. (2008). "Ensuring the effectiveness of a knowledge management initiative". Journal of Knowledge Management, Vol. 12, pp. 16-29.

- Blackler, F. (1995). "Knowledge, knowledge work and organizations: an overview and interpretation". Organization studies, Vol. 16, pp. 1021.

- Boda, G. \& Szlavik, P. (2007). "Alternative accounting to manage intellectual capital". Electronic Journal of Knowledge Management, Vol. 5, pp. 7-18.

- Bontis, N. (1998). "Intellectual capital: an exploratory study that develops measures and models". Management Decision, Vol. 36, pp. 63-76.

- Bontis, N. (1999). "Managing organisational knowledge by diagnosing intellectual capital: framing and advancing the state of the field". International Journal of Technology Management, Vol. 18, pp. 433-462.

- Bontis, N. (2004). "National Intellectual Capital Index: A United Nations initiative for the Arab region". Journal of Intellectual Capital, Vol. 5, pp. 13-39.

- Bontis, N. \& Serenko, A. (2009). "A follow-up ranking of academic journals". Journal of Knowledge Management, Vol. 13, pp. 16-26.

- Booker, L. D., Bontis, N. \& Serenko, A. (2008). "The relevance of knowledge management and intellectual capital Research". Knowledge and process management, Vol. 15, pp. 235-246.

- Brooking, A. (1996). Intellectual capital, Thomson Learning.

- Call, D. (2005). "Knowledge management - not rocket science". Journal of Knowledge Management, Vol. 9, pp. 19-30.

- Carlsson, S. (2003). "Knowledge managing and knowledge management systems in inter-organizational networks". Knowledge and process management, Vol. 10, pp. 194-206.

- Carlsson, S., El Sawy, O., Eriksson, I. \& Raven, A. Gaining competitive advantage through shared knowledge creation: in search of a new design theory for strategic information systems. 1996. 1067ñ1075.

- Carrillo, P., Robinson, H., Anumba, C. \& Al-Ghassani, A. (2003). "IMPaKT: A framework for linking knowledge management to business performance". Electronic Journal of Knowledge Management, Vol. 1, pp. 1-12.

- Carson, E., Ranzijn, R., Winefield, A. \& Marsden, H. (2004). "Intellectual capital: Mapping employee and work group attributes". Journal of Intellectual Capital, Vol. 5, pp. 443-463.

- Chang Lee, K., Lee, S. \& Kang, I. W. (2005). "KMPI: measuring knowledge management performance". Information \& Management, Vol. 42, pp. 469-482.

- Chatzkel, J. (1998). "Measuring and valuing intellectual capital: from knowledge management to knowledge measurement". Journal of Systemic Knowledge Management, Vol., pp.

- Chen, C. J. \& Huang, J. W. (2007). "How organizational climate and structure affect knowledge management-The social interaction perspective". International Journal of Information Management, Vol. 27, pp. 104-118. 
- Chen, J., Sun, P. \& Mcqueen, R. (2010). "The impact of national cultures on structured knowledge transfer". Journal of Knowledge Management, Vol. 14, pp. 228242.

- Chen, J., Zhu, Z. \& Xie, H. Y. (2004). "Measuring intellectual capital: a new model and empirical study". Journal of Intellectual Capital, Vol. 5, pp. 195-212.

- Chen, M., Huang, M. \& Cheng, Y. (2009). "Measuring knowledge management performance using a competitive perspective: An empirical study". Expert Systems with Applications, Vol. 36, pp. 8449-8459.

- Chong, S. C., Salleh, K., Ahmad, S. N. S. \& Sharifuddin, S.-I. S. O. (2011). "KM implementation in a public sector accounting organization: an empirical investigation". Journal of Knowledge Management, Vol. 15, pp. 497-512.

- Claver-Cortes, E., Zaragoza-Saez, P. \& Pertusa-Ortega, E. (2007). "Organizational structure features supporting knowledge management processes". Journal of Knowledge Management, Vol. 11, pp. 45-57.

- Cleveland, A. B. J. (1999). "Knowledge Management: Why It's Not an Information Technology Issue". Journal of Management in Engineering, Vol. 15, pp. 28-28.

- Cranfield, D. \& Taylor, J. (2008). "Knowledge Management and Higher Education: A UK Case Study". The Electronic Journal of Knowledge Management, Vol. 6, pp. 85100.

- Crilly, T., Jashapara, A. \& Ferlie, E. (2010). "Research Utilisation \& Knowledge Mobilisation: A Scoping Review of the Literature". London: Department of Management, Kingís College London, Vol., pp.

- Damodaran, L. \& Olphert, W. (2000). "Barriers and facilitators to the use of knowledge management systems". Behaviour \& Information Technology, Vol. 19, pp. 405-413.

- Dani, S., Harding, J. A., Case, K., Young, R. I. M., Cochrane, S., Gao, J. \& Baxter, D. (2006). "A methodology for best practice knowledge management". Proceedings of the Institution of Mechanical Engineers, Part B: Journal of Engineering Manufacture, Vol. 220, pp. 1717-1728.

- Dave, B. \& Koskela, L. (2009). "Collaborative knowledge management-A construction case study". Automation in Construction, Vol. 18, pp. 894-902.

- Davenport, T. \& Prusak, L. (2000). Working knowledge: How organizations manage what they know, Harvard Business Press.

- Delen, D. \& Al-Hawamdeh, S. (2009). "A holistic framework for knowledge discovery and management". Communications of the ACM, Vol. 52, pp.

- Diakoulakis, I., Georgopoulos, N., Koulouriotis, D. \& Emiris, D. (2004). "Towards a holistic knowledge management model". Journal of Knowledge Management, Vol. 8, pp. 32-46.

- Du Plessis, M. (2005). "Drivers of knowledge management in the corporate environment". International journal of information management, Vol. 25, pp. 193202.

- Du Plessis, M. (2007). "Knowledge management: what makes complex implementations successful?". Journal of Knowledge Management, Vol. 11, pp. 91101.

- Duffy, J. (2000). "Something funny is happening on the way to knowledge management". Information Management Journal, Vol. 34, pp. 64-8.

- Dumay, J. C. (2012). "Grand theories as barriers to using IC concepts". Journal of Intellectual Capital, Vol. 13, pp. 4-15. 
- Edvinsson, L. (1997). "Developing intellectual capital at Skandia". Long Range Planning, Vol. 30, pp. 366-373.

- Edvinsson, L. \& Kivikas, M. (2007). "Intellectual capital (IC) or Wissensbilanz process: some German experiences". Journal of Intellectual Capital, Vol. 8, pp. 376385.

- Erden, Z., Von Krogh, G. \& Nonaka, I. (2008). "The quality of group tacit knowledge". Journal of Strategic Information Systems, Vol. 17, pp. 4-18.

- Evangelista, P., Esposito, E., Lauro, V. \& Raffa, M. (2010). "The Adoption of Knowledge Management Systems in Small Firms". Electronic Journal of Knowledge Management, Vol. 8, pp. 33-42.

- Fahey, L. \& Prusak, L. (1998). "The Eleven Deadliest Sins of Knowledge Management". Vol., pp.

- Faucher, J., Everett, A. \& Lawson, R. (2008). "Reconstituting knowledge management". Journal of Knowledge Management, Vol. 12, pp. 3.

- Feng, K., Chen, E. \& Liou, W. (2004). "Implementation of knowledge management systems and firm performance: an empirical investigation". Journal of Computer Information Systems, Vol. 45, pp. 92-104.

- Flamholtz, E. G., Bullen, M. L. \& Hua, W. (2002). "Human resource accounting: a historical perspective and future implications". Management Decision, Vol. 40, pp. 947-954.

- Forstenlechner, I., Lettice, F. \& Bourne, M. (2009). "Knowledge pays: evidence from a law firm". Journal of Knowledge Management, Vol. 13, pp. 56-68.

- Fugate, B. S., Stank, T. P. \& Mentzer, J. T. (2009). "Linking improved knowledge management to operational and organizational performance". Journal of Operations Management, Vol. 27, pp. 247-264.

- Galbraith, J. K. (1969). The New Industrial State, Princeton University Press.

- Garcia-Perez, A. \& Ayres, R. (2010). "Wikifailure: the Limitations of Technology for Knowledge Sharing". Electronic Journal of Knowledge Management, Vol. 8, pp. 4352.

- Glaser, B. \& Strauss, A. 1967. The discovery of grounded theory. Chicago: Aldine Publishing.

- Gold, A. H., Malhotra, A. \& Segars, A. H. (2001). "Knowledge management: An organizational capabilities perspective". Journal of management information systems, Vol. 18, pp. 185-214.

- Goldoni, V. \& Oliveira, M. (2010). "Knowledge management metrics in software development companies in Brazil". Journal of Knowledge Management, Vol. 14, pp. 301-313.

- Grace, T. (2009). "Wikis as a knowledge management tool". Journal of Knowledge Management, Vol. 13, pp. 64-74.

- Grant, K. (2007). "Tacit knowledge revisitedñwe can still learn from Polanyi". The Electronic Journal of Knowledge Management, Vol. 5, pp. 173-180.

- Hallin, C. \& Marnburg, E. (2008). "Knowledge management in the hospitality industry: A review of empirical research". Tourism Management, Vol. 29, pp. 366381.

- Hansen, M., Nohria, N. \& Tierney, T. (1999). "What is your strategy for managing knowledge?". Harvard Business Review, Vol., pp.

- Harlow, H. (2008). "The effect of tacit knowledge on firm performance". Journal of Knowledge Management, Vol. 12, pp. 148. 
- Hawkins, S. (2001). "Intangible asset and value creation reporting...increasing transparency at Skandia". Journal of Financial Transformation, Vol. 3, pp. 127-133.

- Hazlett, S.-A., Mcadam, R. \& Gallagher, S. (2005). "Theory Building in Knowledge Management: In Search of Paradigms". Journal of Management Inquiry, Vol. 14, pp. 31-42.

- Heisig, P. (2002). "European Guide to Good Practice in Knowledge Management Frameworks on Knowledge Management". Presentation on, Vol. 14, pp.

- Heisig, P. (2009). "Harmonisation of knowledge management - Comparing 160 KM frameworks around the globe". Journal of Knowledge Management, Vol. 13, pp. 431.

- Hermanson, R. H. (1964). Accounting for human assets, Bureau of Business and Economic Research, Graduate School of Business Administration, Michigan State University.

- Hicks, R. C., Dattero, R. \& Galup, S. D. (2006). "The five-tier knowledge management hierarchy". Journal of Knowledge Management, Vol. 10, pp. 19-31.

- Hislop, D. (2009). Knowledge management in organizations, Oxford University Press London.

- Hofer-Alfeis, J. (2008). "Knowledge management solutions for the leaving expert issue". Journal of Knowledge Management, Vol. 12, pp. 44-54.

- Hofstede, G., Hofstede, G. J. \& Minkov, M. (1991). Cultures and organizations, McGraw-Hill London.

- Holsapple, C. \& Joshi, K. Description and analysis of existing knowledge management frameworks. 1999. Citeseer, 45-45.

- Holsapple, C. W. (2001). "Knowledge management support of decision making". Decision Support Systems, Vol. 31, pp. 1-3.

- Holste, J. S. \& Fields, D. (2010). "Trust and tacit knowledge sharing and use". Journal of Knowledge Management, Vol. 14, pp. 128-140.

- Hong Pew, T., David, P. \& Phil, H. (2008). "The evolving research on intellectual capital". Journal of Intellectual Capital, Vol. 9, pp. 585-608.

- Huang, M. J., Chen, M. Y. \& Yieh, K. (2007). "Comparing with your main competitor: the single most important task of knowledge management performance measurement". Journal of Information Science, Vol. 33, pp. 416-434.

- Ibrahim, F. \& Reid, V. (2009). "What is the Value of Knowledge Management Practices?". Electronic Journal of Knowledge Management, Vol. 7, pp. 567-574.

- Iske, P. \& Boekhoff, T. (2002). "The value of Knowledge doesn't exist". Practical Aspects of Knowledge Management, Vol., pp. 632-638.

- Jacobsen, K., Hofman-Bang, P. \& Nordby Jr, R. (2005). "The IC Rating". Journal of Intellectual Capital, Vol. 6, pp. 570-587.

- Jakubik, M. (2007). "Exploring the knowledge landscape: four emerging views of knowledge". Journal of Knowledge Management, Vol. 11, pp. 6 ñ19.

- James, P. Strategic Management Meets Knowledge Management: a literature review and theoretical framework. 2004.

- Jesson, J., Matheson, L. \& Lacey, F. (2011). Doing your literature review: Traditional and systematic techniques, Sage Los Angeles.

- Johnson, W. (2007). "Mechanisms of tacit knowing: pattern recognition and synthesis". Journal of Knowledge Management, Vol. 11, pp. 123-139.

- Kahneman, D. (2011). Thinking, fast and slow, Farrar, Straus and Giroux.

- Kalling, T. (2003). "Knowledge management and the occasional links with performance". Journal of Knowledge Management, Vol. 7, pp. 67-81. 
- Kamara, J. M., Anumba, C. J. \& Carrillo, P. M. (2002). "A CLEVER approach to selecting a knowledge management strategy". International Journal of Project Management, Vol. 20, pp. 205-211.

- Kamhawi, E. M. (2012). "Knowledge management fishbone: a standard framework of organizational enablers". Journal of Knowledge Management, Vol. 16, pp. 808-828.

- Kankanhalli, A. \& Tan, B. (2005). "Knowledge management metrics: A review and directions for future research". International Journal of Knowledge Management, Vol. 1, pp. 20.

- Kannabiran, G. \& Pandyan, C. (2010). "Enabling role of governance in strategizing and implementing KM". Journal of Knowledge Management, Vol. 14, pp. 335-347.

- Kannan, G. \& Aulbur, W. G. (2004). "Intellectual capital: measurement effectiveness". Journal of Intellectual Capital, Vol. 5, pp. 389-413.

- Kaplan, R. \& Norton, D. (1995). "Putting the balanced scorecard to work". Performance measurement, management, and appraisal sourcebook, Vol., pp. 66.

- Khalifa, M., Yu, A. \& Shen, K. (2008). "Knowledge management systems success: a contingency perspective". Journal of Knowledge Management, Vol. 12, pp. 119.

- Kidwell, J. J., Vander Linde, K. \& Johnson, S. L. (2000). "Applying Corporate Knowledge Management Practices in Higher Education". Educause Quarterly, Vol. 23, pp. 28-33.

- Kwee Keong, C. (2008). "Intellectual capital: definitions, categorization and reporting models". Journal of Intellectual Capital, Vol. 9, pp. 609-638.

- Lam, A. \& Lambermont-Ford, J. (2010). "Knowledge sharing in organisational contexts: a motivation-based perspective". Journal of Knowledge Management, Vol. 14, pp. 51-66.

- Lambe, P. (2011). "The unacknowledged parentage of knowledge management". Journal of Knowledge Management, Vol. 15, pp. 175-197.

- Lang, J. (2001). "Managerial concerns in knowledge management". Journal of Knowledge Management, Vol. 5, pp. 43-57.

- Leonard, D. (1995). Wellspring of knowledge, Harvard Business School Press Boston, MA.

- Lerro, A., Iacobone, F. A. \& Schiuma, G. (2012). "Knowledge assets assessment strategies: organizational value, processes, approaches and evaluation architectures". Journal of Knowledge Management, Vol. 16, pp. 563-575.

- Lev, B. \& Feng, G. Intangible assets: measurement, drivers, usefulness. Advances in the Measurement of Intangible (Intellectual) Capital Conference, 2001 New York University, New York.

- Levy, M. (2009). "WEB 2.0 implications on knowledge management". Journal of Knowledge Management, Vol. 13, pp. 120-134.

- Levy, M., Hadar, I., Greenspan, S. \& Hadar, E. (2010). "Uncovering cultural perceptions and barriers during knowledge audit". Journal of Knowledge Management, Vol. 14, pp. 114-127.

- Liao, S. (2003). "Knowledge management technologies and applications-literature review from 1995 to 2002". Expert Systems with Applications, Vol. 25, pp. 155-164.

- Liebowitz, J. \& Suen, C. (2000). "Developing knowledge management metrics for measuring intellectual capital". Journal of Intellectual Capital, Vol. 1, pp. 54-67.

- Liebowitz, J. \& Wright, K. (1999). "Does measuring knowledge make"cents"?". Expert Systems with Applications, Vol. 17, pp. 99-103.

- Lin, H.-F. (2011). "Antecedents of the stage-based knowledge management evolution". Journal of Knowledge Management, Vol. 15, pp. 136-155. 
- Lindvall, M., Rus, I. \& Sinha, S. (2003). "Software systems support for knowledge management". Journal of Knowledge Management, Vol. 7, pp. 137.

- Ling, C. T. N. (2011). "Culture and Trust in Fostering Knowledge-Sharing". Electronic Journal of Knowledge Management, Vol. 9, pp.

- Lloria, M. B. (2008). "A review of the main approaches to knowledge management". Knowledge Management Research \& Practice, Vol. 6, pp. 77-89.

- Lundvall, B. (1996). "The social dimension of the learning economy". Vol., pp.

- Luthy, D. Intellectual capital and its measurement. 1998.

- Ma, Z. \& Yu, K. (2010). "Research paradigms of contemporary knowledge management studies: 1998-2007". Journal of Knowledge Management, Vol. 14, pp. 175-189.

- Magnier-Watanabe, R., Benton, C. \& Senoo, D. (2011). "A study of knowledge management enablers across countries". Knowledge Management Research \& Practice, Vol. 9, pp. 17-28.

- Mahesh, K. \& Suresh, J. K. (2009). "Knowledge criteria for organization design". Journal of Knowledge Management, Vol. 13, pp. 41-51.

- Maier, R. (2002). Knowledge Management Systems, Springer Berlin.

- Marr, B., Schiuma, G. \& Neely, A. (2004). "Intellectual capital, Defining key performance indicators for organizational knowledge assets". Business Process Management Journal, Vol. 10, pp. 551-569.

- Marti, J. M. V. (2001). "ICBS - intellectual capital benchmarking system". Journal of Intellectual Capital, Vol. 2, pp. 148-165.

- Marti, J. M. V. (2004). "Strategic knowledge benchmarking system (SKBS): a knowledge-based strategic management information system for firms". Journal of Knowledge Management, Vol. 8, pp. 31-49.

- Martí, J. M. V. (2007). "In search of an intellectual capital comprehensive theory". Electronic Journal of Knowledge Management, Vol. 5, pp. 245-256.

- Martin, W. J. (2004). "Demonstrating knowledge value: a broader perspective on metrics". Journal of Intellectual Capital, Vol. 5, pp. 77-91.

- Martins, E. C. \& Meyer, H. W. J. (2012). "ORGANISATIONAL AND BEHAVIOURAL FACTORS THAT INFLUENCE KNOWLEDGE RETENTION". Journal of Knowledge Management, Vol. 16, pp. 5-5.

- Mason, D. \& Pauleen, D. (2003). "Perceptions of knowledge management: a qualitative analysis". Journal of Knowledge Management, Vol. 7, pp. 38-48.

- Massa, S. \& Testa, S. (2009). "A knowledge management approach to organizational competitive advantage: Evidence from the food sector". European Management Journal, Vol. 27, pp. 129-141.

- Mayo, A. (2001). The human value of the enterprise: Valuing people as assets: Monitoring, measuring, managing, Nicholas Brealey Publishing.

- Mciver, D., Lengnick-Hall, C. A., Lengnick-Hall, M. L. \& Ramachandran, I. (2012). "Integrating knowledge and knowing: A framework for understanding knowledge-inpractice". Human Resource Management Review, Vol. 22, pp. 86-99.

- Mcqueen, R. Four views of knowledge and knowledge management. 1998. Citeseer, 609-611.

- Metaxiotis, K., Ergazakis, K. \& Psarras, J. (2005). "Exploring the world of knowledge management: agreements and disagreements in the academic/practitioner community". Journal of Knowledge Management, Vol. 9, pp. 6-18. 
- Millar, J., Demaid, A. \& Quintas, P. (1997). "Trans-organizational innovation: a framework for research". Technology Analysis \& Strategic Management, Vol. 9, pp. 399-418.

- Mills, A. M. \& Smith, T. A. (2011). "Knowledge management and organizational performance: a decomposed view". Journal of Knowledge Management, Vol. 15, pp. 156-171.

- Mitchell, R. \& Boyle, B. (2010). "Knowledge creation measurement methods". Journal of Knowledge Management, Vol. 14, pp. 67-82.

- Mohamed, M., Murray, A. \& Mohamed, M. (2010). "The role of information and communication technology (ICT) in mobilization of sustainable development knowledge: a quantitative evaluation". Journal of Knowledge Management, Vol. 14, pp. 744-758.

- Moss, G., Kubacki, K., Hersh, M. \& Gunn, R. (2007). "Knowledge Management in Higher Education: a comparison of individualistic and collectivist cultures". European Journal of Education, Vol. 42, pp. 377-394.

- Moteleb, A. \& Woodman, M. (2007). "Notions of knowledge management systems: a gap analysis". The Electronic Journal of Knowledge Management, Vol. 5, pp. 55-62.

- Mouritsen, J. \& Larsen, H. T. (2005). "The 2nd wave of knowledge management: The management control of knowledge resources through intellectual capital information". Management accounting research, Vol. 16, pp. 371-394.

- Mullich, J. (2001). "Growing a knowledge management system". EDPACS, Vol. 28, pp. 17-17.

- Nicolas, R. (2004). "Knowledge management impacts on decision making process". Journal of Knowledge Management, Vol. 8, pp. 20-31.

- Nonaka, I. A. \& Takeuchi, H. A. (1995). The knowledge-creating company: How Japanese companies create the dynamics of innovation, Oxford university press.

- Norton, D. P. (2001). "Managing the Development of Human Capital". Balanced Scorecard Report, Vol. 3, pp.

- O'dell, C., O'dell, C., Grayson, C. \& Essaides, N. (1998). If only we knew what we know: The transfer of internal knowledge and best practice, Free Pr.

- O'donohue, W., Sheehan, C., Hecker, R. \& Holland, P. (2007). "The psychological contract of knowledge workers". Journal of Knowledge Management, Vol. 11, pp. 7382.

- Oguz, F. \& Sengün, A. E. (2011). "Mystery of the unknown: revisiting tacit knowledge in the organizational literature". Journal of Knowledge Management, Vol. 15, pp. 445-461.

- Parise, S., Cross, R. \& Davenport, T. H. (2006). "Strategies for preventing a knowledge-loss crisis". MIT sloan management review, Vol. 47, pp. 31-31.

- Paroutis, S. \& Saleh, A. (2009). "Determinants of knowledge sharing using Web 2. 0 technologies". Journal of Knowledge Management, Vol. 13, pp. 52-63.

- Paul Ihuoma, O. (2012). "Developing a Corporate Knowledge Management Strategy". Journal of Knowledge Management, Vol. 16, pp. 2-2.

- Petra, A. \& Annelies, W. (2012). "Disentangling value-enhancing and cost-increasing effects of knowledge management". Journal of Knowledge Management, Vol. 16, pp. 387-399.

- Petty, R. \& Guthrie, J. (2000). "Intellectual capital literature review: Measurement, reporting and management". Journal of Intellectual Capital, Vol. 1, pp. 155-176.

- Polanyi, M. (1967). "The tacit dimension". New York, Vol., pp. 
- Poston, R. S. \& Speier, C. (2005). "Effective use of knowledge management systems: A process model of content ratings and credibility indicators". MIS quarterly, Vol., pp. 221-244.

- Pulic, A. (2000). "VAICTM - an accounting tool for IC management". International Journal of Technology Management, Vol. 20, pp. 702-714.

- Quaddus, M. \& Xu, J. (2005). "Adoption and diffusion of knowledge management systems: field studies of factors and variables". Knowledge-Based Systems, Vol. 18, pp. 107-115.

- Renzl, B. (2008). "Trust in management and knowledge sharing: The mediating effects of fear and knowledge documentation". Omega, Vol. 36, pp. 206-220.

- Robinson, G. \& Kleiner, B. H. (1996). "How to measure an organizations intellectual capital". Managerial Auditing Journal, Vol. 11, pp. 36-39.

- Romer, P. M. (1986). "Increasing returns and long-run growth". The Journal of Political Economy, Vol., pp. 1002-1037.

- Roos, G. \& Roos, J. (1997). "Measuring your company's intellectual performance". Long Range Planning, Vol. 30, pp. 413-426.

- Roos, J., Edvinsson, L. \& Roos, G. (1998). Intellectual capital: navigating in the new business landscape, New York University Press.

- Roy, R., Van Wegen, B. \& Steele, A. (2003). "A framework to create key performance indicators for knowledge management solutions". Journal of Knowledge Management, Vol. 7, pp. 46-62.

- Ruggles, R. (1999). "The state of the notion: knowledge management in practice". The Knowledge Management Yearbook 1999-2000, Vol., pp. 295.

- Rynes, S. L., Bartunek, J. M. \& Daft, R. L. (2001). "Across the Great Divide: Knowledge Creation and Transfer between Practitioners and Academics". Academy of management Journal, Vol. 44, pp. 340-355.

- Sangjae, L., Byung Gon, K. \& Hoyal, K. (2012). "An integrated view of knowledge management for performance". Journal of Knowledge Management, Vol. 16, pp. 183203.

- Schroeder, A., Pauleen, D. \& Huff, S. (2012). "KM Governance: the mechanisms for guiding and controlling KM programs". Journal of Knowledge Management, Vol. 16, pp. 1-1.

- Schubert, P., Lincke, D. \& Schmid, B. A global knowledge medium as a virtual community: the NetAcademy concept. Americas Conference of AIS, 1998.

- Seba, I. \& Rowley, J. (2010). "Knowledge management in UK police forces". Journal of Knowledge Management, Vol. 14, pp. 611-626.

- Serban, A. M. \& Luan, J. (2002). "Overview of knowledge management". New Directions for Institutional Research, Vol. 2002, pp. 5-16.

- Serenko, A. \& Bontis, N. (2004). "Meta-review of knowledge management and intellectual capital literature: citation impact and research productivity rankings". Knowledge and process management, Vol. 11, pp. 185-198.

- Serenko, A., Bontis, N., Booker, L., Sadeddin, K. \& Hardie, T. (2010). "A scientometric analysis of knowledge management and intellectual capital academic literature(1994-2008)". Journal of Knowledge Management, Vol. 14, pp. 3-23.

- Shin, M. (2004). "A framework for evaluating economics of knowledge management systems". Information \& Management, Vol. 42, pp. 179-196.

- Sié, L. \& Yakhlef, A. (2009). "Passion and expertise knowledge transfer". Journal of Knowledge Management, Vol. 13, pp. 175-186. 
- Sieloff, C. (1999). "If only HP knew what HP knows: The roots of knowledge management at Hewlett-Packard". Journal of Knowledge Management, Vol. 3, pp. 47-53.

- Skyrme, D. (2003). "Measuring Knowledge and Intellectual Capital". Business Intelligence, Vol., pp.

- Snowden, D. (2002). "Complex acts of knowing: paradox and descriptive selfawareness". Journal of Knowledge Management, Vol. 6, pp. 100-111.

- Ståhle, P., Ståhle, S. \& Aho, S. (2011). "Value added intellectual coefficient (VAIC): a critical analysis". Journal of Intellectual Capital, Vol. 12, pp. 531-551.

- Stern, J. M., Stewart, G. B. \& Chew, D. (1995). "The EVA financial management system". Journal of Applied Corporate Finance, Vol. 8, pp. 32-46.

- Stevens, R., Millage, J. \& Clark, S. (2010). "Waves of Knowledge Management: The Flow between Explicit and Tacit Knowledge". American Journal of Economics and Business Administration, Vol. 2, pp. 129-135.

- Stewart, B. (1994). "EVA: fact and fantasy»". Journal of Applied Corporate Finance, Vol. 7, pp. 71-87.

- Stewart, T. (1998). Intellectual Capital: The New Wealth of Organizations, Doubleday New York, NY.

- Stewart, T. \& Ruckdeschel, C. (1998). "Intellectual capital: The new wealth of organizations". Performance Improvement, Vol. 37, pp. 56-59.

- Storey, J. \& Barnett, E. (2000). "Knowledge management initiatives: learning from failure". Journal of Knowledge Management, Vol. 4, pp. 145-156.

- Suppiah, V. \& Sandhu, M. S. (2011). "Organisational culture's influence on tacit knowledge-sharing behaviour". Journal of Knowledge Management, Vol. 15, pp. 462477.

- Susanne, D. \& Ingi Runar, E. (2012). "Knowledge Management in SMEs: A Literature Review". Journal of Knowledge Management, Vol. 16, pp. 3-3.

- Susanne, D. \& Stefan, W. (2012). "Knowledge management and succession planning in SMEs". Journal of Knowledge Management, Vol. 16, pp. 637-649.

- Sveiby, K. E. (1997). The new organizational wealth: Managing \& measuring knowledge-based assets, Berrett-Koehler Pub.

- Swift, M., Balkin, D. B. \& Matusik, S. F. (2010). "Goal orientations and the motivation to share knowledge". Journal of Knowledge Management, Vol. 14, pp. 378-393.

- Syed, J. (1998). "An adaptive framework for knowledge work". Journal of Knowledge Management, Vol. 2, pp. 59-69.

- Tobin, J. (1969). "A general equilibrium approach to monetary theory". Journal of money, credit and banking, Vol. 1, pp. 15-29.

- Tranfield, D., Denyer, D. \& Smart, P. (2003). "Towards a methodology for developing evidence $\square$ informed management knowledge by means of systematic review". British journal of management, Vol. 14, pp. 207-222.

- Tseng, S.-M. (2010). "The correlation between organizational culture and knowledge conversion on corporate performance". Journal of Knowledge Management, Vol. 14, pp. 269-284.

- Tsui, E. (2005). "The role of IT in KM: where are we now and where are we heading". Journal of Knowledge Management, Vol. 9, pp. 3-6.

- Vestal, W. (2002). "Measuring knowledge management". Retrieved July, Vol. 7, pp. 2003. 
- Vilma, V. \& Jussi, O. (2012). "Knowledge sharing motivational factors of using an intra-organizational social media platform". Journal of Knowledge Management, Vol. 16, pp. 592-603.

- Wang, D., Su, Z. \& Yang, D. (2011). "Organizational culture and knowledge creation capability". Journal of Knowledge Management, Vol. 15, pp. 363-373.

- Weaver, S. C. (2001). "Measuring economic value added: A survey of the practices of EVA proponents". Journal of Applied Finance, Vol. 11, pp. 50-60.

- Wen, Y.-F. (2009). "An effectiveness measurement model for knowledge management". Knowledge-Based Systems, Vol. 22, pp. 363-367.

- Whelan, E., Collings, D. \& Donnellan, B. (2010). "Managing talent in knowledgeintensive settings". Journal of Knowledge Management, Vol. 14, pp. 486-504.

- Wiig, K. M. (2007). "Effective societal knowledge management". Journal of Knowledge Management, Vol. 11, pp. 141-156.

- Wilson, T. D. (2002). "The nonsense of knowledge management". Information research, Vol. 8, pp. 8-1.

- Wyatt, W. 2001. Study Identifies Certain HR Practices as Leading Indicators of Financial Success [Online]. Available: http://www.watsonwyatt.com/render.asp?catid=1\&id=9047 [Accessed 1 May 2012].

- Wyatt's, W. (2001). "Human Capital Index®". Vol., pp.

- Xue, Y., Bradley, J. \& Liang, H. (2011). "Team climate, empowering leadership, and knowledge sharing". Journal of Knowledge Management, Vol. 15, pp. 299-312.

- Yahya, S. \& Goh, W. (2002). "Managing human resources toward achieving knowledge management". Journal of Knowledge Management, Vol. 6, pp. 457-468.

- Yigitcanlar, T., Baum, S. \& Horton, S. (2007). "Attracting and retaining knowledge workers in knowledge cities". Journal of Knowledge Management, Vol. 11, pp. 6-17.

- Yu, S., Kim, Y. \& Kim, M. (2007). "Do we know what really drives KM performance?". Journal of Knowledge Management, Vol. 11, pp. 39-53.

- Zack, M. (1999). "Managing codified knowledge". Sloan Management Review, Vol. 40, pp. 45-58.

- Zack, M., Mckeen, J. \& Singh, S. (2009). "Knowledge management and organizational performance: an exploratory analysis". Journal of Knowledge Management, Vol. 13, pp. 392-409.

- Zeleny, M. (2002). "Knowledge of enterprise: knowledge management or knowledge technology?". International Journal of Information Technology \& Decision Making, Vol. 1, pp. 181-207.

- Zelic, B. 2005. Resolving the Codification-Personalisation Dilemma in Knowledge Management: A Case Study of a German Car Manufacturer. Doctor of Philosophy (PhD), Dublin Institute of Technology. 